\title{
Special Issue: the 3rd meeting of the Bergey's International Society for Microbial Systematics (BISMIS)
}

\author{
Brian P. Hedlund - Iain C. Sutcliffe - Martha E. Trujillo
}

Published online: 23 August 2017

(C) Springer International Publishing AG 2017

This Special Issue of Antonie van Leeuwenhoek contains a series of invited papers based on contributions made at the 3rd meeting of the Bergey's International Society for Microbial Systematics (BISMIS), held in Pune, India in September 2016. The local organising committee, led by Professor Yogesh Shouche and convenor Dr Kamlesh Jangid, provided excellent hospitality and a vibrant scientific programme, with 86 registered participants from 15 different countries in attendance. We thank Yogesh, Kamlesh and the local organising committee for all their hard work in providing such an exciting meeting, from which we have been able to draw our Special Issue contributors. Likewise, the financial support of the Bergey's Manual Trust in organising the meeting was much appreciated.

\section{B. P. Hedlund}

School of Life Sciences and Nevada Institute of Personalized Medicine, University of Nevada, Las Vegas, Las Vegas, Nevada 89154-4004, USA

I. C. Sutcliffe $(\bowtie)$

Faculty of Health and Life Sciences, Northumbria University, Newcastle upon Tyne NE1 8ST, UK e-mail: iain.sutcliffe@unn.ac.uk

\section{E. Trujillo}

Departamento de Microbiología y Genética, Campus Miguel de Unamuno, Universidad de Salamanca, 37007 Salamanca, Spain
The 3rd BISMIS meeting in Pune followed on from successful meetings in China (May 2011) and Edinburgh (April 2014). It has been clear at all three of these meetings that systematics remains "a vital discipline entering a period of transition" (Sutcliffe et al. 2012). The technological impact of nextgeneration sequencing has already revolutionised our understanding of the vast microbial majority of 'as yet uncultivated' microorganisms and has also begun to influence how microbial taxa are delineated and described. These are exciting developments which we hope will serve to attract young microbiologists into the field. The 4th BISMIS meeting will be held in South Africa in April 2018, with Professor Stephanus Venter as convenor (for details see http://www.bismis. co.za/). We are sure that this will prove to be another exciting meeting, providing more evidence for the progression of the discipline, and we hope that you will be able to attend.

\section{Footnote from the Editor-in-Chief}

This Special Issue marks the last Editorial contribution to Antonie van Leeuwenhoek of Professor Martha Trujillo. Martha has worked hard on behalf of the journal since 2009. During this time Antonie van Leeuwenhoek has developed a strong profile as a journal publishing significant studies in microbial systematics (Sutcliffe and Trujillo 2013) and Martha 
has played a significant part in that process. I thank her greatly, on behalf of both the Editorial Board and our publisher Springer, and wish her good luck and success in her new role as Editor-in-Chief of the International Journal of Systematic and Evolutionary Microbiology.

\section{References}

Sutcliffe IC, Trujillo ME (2013) Publication of descriptions of novel bacterial taxa in Antonie van Leeuwenhoek. Antonie Van Leeuwenhoek 2013(103):1-2

Sutcliffe IC, Trujillo ME, Goodfellow M (2012) The BISMiS 2011 special issue on prokaryotic systematics, a vital discipline entering a period of transition. Antonie Van Leeuwenhoek 2012(101):1-2 